\title{
DETECTION OF EPILEPSY USING ADAPTIVE NEURO-FUZZY INFERENCE SYSTEM
}

\author{
Marjan Stoimchev, Vesna Ojleska Latkoska \\ Faculty of Electrical Engineering and Information Technologies, \\ "Ss. Cyril and Methodius" University in Skopje, \\ Rugjer Bošković bb, P.O. box 574, 1001 Skopje, Republic of Macedonia \\ vojleska@feit.ukim.edu.mk
}

\begin{abstract}
A b s t r a c t: This study presents the use of Adaptive Neuro-Fuzzy Inference System (ANFIS) for classification of the EEG signals. The data consists of two types of EEG signals, i.e. epileptic patients during epilepsy and healthy patients when their eyes are open. The proposed algorithm has several steps. First, in order to remove the artefacts (filter the signals) we use band-pass Finite Impulse Response (FIR) filtering with the Hamming window. Feature extraction is made in the second step, using Discrete Wavelet Transform (DWT) and statistical analysis. In this way we reduce the dimensionality of the input data, lately used as input parameters in the ANFIS network. ANFIS model learns how to classify the EEG signal, through the standard hybrid learning algorithm. We use special form of ANFIS model, which depending on the number of inputs, splits the model into appropriate number of substructures (sub-ANFIS models). ANFIS model was evaluated in terms of training performance and classification accuracies. From the simulation results it was concluded that the proposed algorithm has good potentials in classifying the EEG signals.
\end{abstract}

Key words: Adaptive Neuro-Fuzzy Inference System (ANFIS); fuzzy logic; wavelet transform; Finite Impulse Response (FIR) filter; electroencephalogram (EEG) signals

\section{ДЕТЕКЦИЈА НА ЕПИЛЕПСИЈА СО ПОМОШ НА АДАПТИВЕН ФАЗИ-НЕВРОНСКИ СИСТЕМ НА ЗАКЛУЧУВАЫЕ}

\begin{abstract}
А п с т р а к т: Овој труд ја презентира употребата на адаптивниот невро-фази-логички механизам на заклучување (Adaptive Neuro-Fuzzy Inference System - ANFIS) за класификација на електроенцефалограмските (ЕEГ) сигнали. Множеството се состои од два типа ЕЕГ сигнали, т.е. на епилептични пациенти за време на епилепсијата и здрави пациенти кога нивните очи се отворени. Претставениот алгоритам има неколку чекори. Прво, со цел да се отстранат артефактите (да се исфилтрираат сигналите) користиме филтер со конечен импулсен одзив (Finite Impulse Response - FIR) со Хамингов прозорец. Во вториот чекор се прави извлекување на карактеристики со користење на дискретна вејвлет-трансформација (Discrete Wavelet Transform - DWT) и статистичка анализа. На овој начин се врши редукција на димензионалноста на влезните податоци, подоцна искористени како влезни параметри во мрежата ANFIS. Моделот ANFIS учи како да се класифицираат EEГсигналите преку стандардниот хибриден алгоритам. Во овој труд се користи специјална форма на моделот ANFIS, кој во зависност од бројот на влезови го дели моделот во соодветен број потструктури (sub-ANFISмодели). Точноста на моделот ANFIS се евалуира врз основа на перформансата на моделот (спроведена на тренинг и тест-множества), како и прецизноста на класификација. Од симулационите резултати може да се заклучи дека претставениот алгоритам има добар потенцијал за класификација на ЕЕГ-сигнали.
\end{abstract}

Клучни зборови: адаптивен неуро-фази механизам на заклучување (ANFIS); фази логика; вејвлет-трансформација; филтер со конечен импулсен одзив; електро-енцефалограмски сигнали (EEG)

\section{INTRODUCTION}

Epilepsy is the most common neurological disorder affecting 50 million people world-wide, $85 \%$ of which belong to the developing countries. Around 2.4 million new cases occur every year globally. At least $50 \%$ of the epileptic cases begin at childhood or adolescence [1]. 
The electroencephalogram (EEG) signal is widely used clinically to investigate brain disorders [14]. Therefore, the study of the brain electrical activity through the EEG records, is one of the most important tools for diagnosis of neurological diseases $[6,8]$. It is possible for experienced neurophysiologist to detect the epilepsy by visually scanning of the EEG signals for pre-ictal, inter-ictal and ictal activities [1]. However, for a more objective analysis and reproducible results, it is always advantageous to detect these activities from the EEG signals through some computer methods by extracting relevant features from the signals. Adeli et al. $[6,8]$ launched the field of automated EEG-based diagnosis by analyzing and characterizing epileptiform discharges using wavelet transform [1]. Some of their studies focus on detecting epilepsy by classifying only the normal and ictal stages (two-class problem), as proposed in these studies $[4,7,13,14]$, and other studies present methods for classifying all three stages, namely normal, interictal, and ictal (three-class problem) [33].

In order to solve the above-mentioned problems, i.e. to make an automated system for epilepsy detection, there are many proposed methodologies. In general, all of the techniques consist of several steps, i.e. from data preprocessing as the first step, through feature extraction as a second step, to classification as a third step.

EEG signals may be corrupted with noises, called artefacts which come from patient's body or instruments (examples include: the eyes, the heart, or the muscles movement, or the power line noise, etc.) [19]. Therefore, removal of these artefacts is a primary task and it forms a fundamental step for EEG signal preprocessing [19]. This task can be solved using conventional filtering methods, or filtering through wavelet analysis [18]. In this study for the purpose of data preprocessing we use conventional band-pass FIR filtering technique that uses Hamming window $[2,3]$.

For the second step, feature extraction takes place. There are many different methods that can be used for this task, whereas those techniques include frequency domain analysis or time domain analysis, or both. Among the techniques that use time-frequency analysis is the wavelet transform (WT) [6, 8]. The results of the studies in the literature have demonstrated that the WT is the most promising method to extract relevant features from the EEG signals $[6.8,13]$. In this respect, in this study the WT was used for feature extraction from the EEG signals $[6,8,13]$.
The final step is classifying the EEG signals. There are also different ways for classifying the EEG signals as proposed in [6]. Some studies use feature extraction method using genetic algorithmbased frequency domain (GAFD) feature search [25], the wavelet-based support vector machine (SVM) classifier [26], wavelet-based feed forward artificial neural network (FFANN) [17, 24], k-Nearest Neighbors classifier [28], fuzzy rule-based detection 27, Adaptive Neuro-Fuzzy Inference System (ANFIS) [13, 14, 4], and many others.

Artificial neural networks (ANNs) have been used as computational tools for pattern classification including diagnosis of diseases because of their great predictive power $[24,30]$. On the other hand, fuzzy set theory plays an important role in dealing with uncertainty when making decisions in medical applications [10, 31, 32]. Neuro-fuzzy systems are fuzzy systems, which use ANNs theory in order to determine their properties (fuzzy sets and fuzzy rules) by processing data samples [10]. A specific approach in neuro-fuzzy development is the ANFIS [10], which has shown significant results in modeling nonlinear functions. When input data is given, ANFIS learns features and adjust the parameters of the system according to a given error criterion [10]. There are many successful implementations of ANFIS in the biomedical field of engineering, i.e. classification of data $[11,12,13,14]$, and data analysis [15].

In this study we present the use of ANFIS for classification of the EEG signals, whereas the data consist of two types of EEG signals, i.e. epileptic patients during epilepsy and healthy patients when their eyes are open. We use two sets of data, described in [16], whereas $S$ is the data set that contains epileptic patients and $Z$ is the data set that contains healthy patients. The proposed algorithm has several steps. First, in order to remove the artefacts (filter the signals) we use band-pass finite impulse response (FIR) filtering with the Hamming window. Feature extraction is made in the second step, using discrete wavelet transform (DWT) and statistical analysis $[13,14]$. In this way we reduce the dimensionally of the input data, lately used as input parameters in the ANFIS network. We also perform normalization of the data, before it is used for the process of training of the ANFIS. This method is also called feature scaling method which will enable a better convergence when adapting the weighted factors in the ANFIS model during the training process. ANFIS model learns how to classify the EEG 
signal, through the standard hybrid learning algorithm. We use a special form of ANFIS model, which depending on the number of inputs, splits the model into appropriate number of substructures (sub-ANFIS models). ANFIS model was evaluated in terms of training performance and classification accuracies. From the simulation results it was concluded that the proposed algorithm has good potentials in classifying the EEG signals.

Authors in $[4,14]$ also use wavelet transform for feature extraction and ANFIS for classification of EEG signals, but our approach differs from theirs as we use conventional filtering method (FIR), as well as normalization of the data after feature extraction. Our approach gives similar, or somewhere even better results, which is summarized in the Section 3.

This paper is organized as follows: in Section 2 we give a brief introduction to the methodologies used in the algorithm (FIR filtering, wavelet transform, and ANFIS). In Section 3 we propose the overall algorithm for EEG signals classification, after which in Section 4 we conclude the paper with the necessary conclusions.

\section{MATERIALS AND METHOD}

The algorithm for detection of epilepsy with fuzzy-neural networks for classification of EEG signals in Section 3 consists of several steps, which include:

1) Filtering of the EEG signals with FIR filter.

2) Feature extraction and dimensionality reduction with discrete wavelet transform (DWT).

3) Classification using ANFIS.

The general steps are given in Figure 1 and their detailed analyses are presented in Section 3.

A brief introduction of these methodologies is given bellow.

\subsection{Signal De-Noising with FIR filter}

Filtering is the process of selectively allowing certain frequencies (or range of frequencies) in a signal and attenuating frequency components outside the desired range. In most instances, the objective of filtering is to eliminate or reduce the amount of undesired noise that may be corrupting a signal of interest. In some cases, the objective may simply be to manipulate the relative frequency conent of a signal in order to change its spectral characteristics [2].

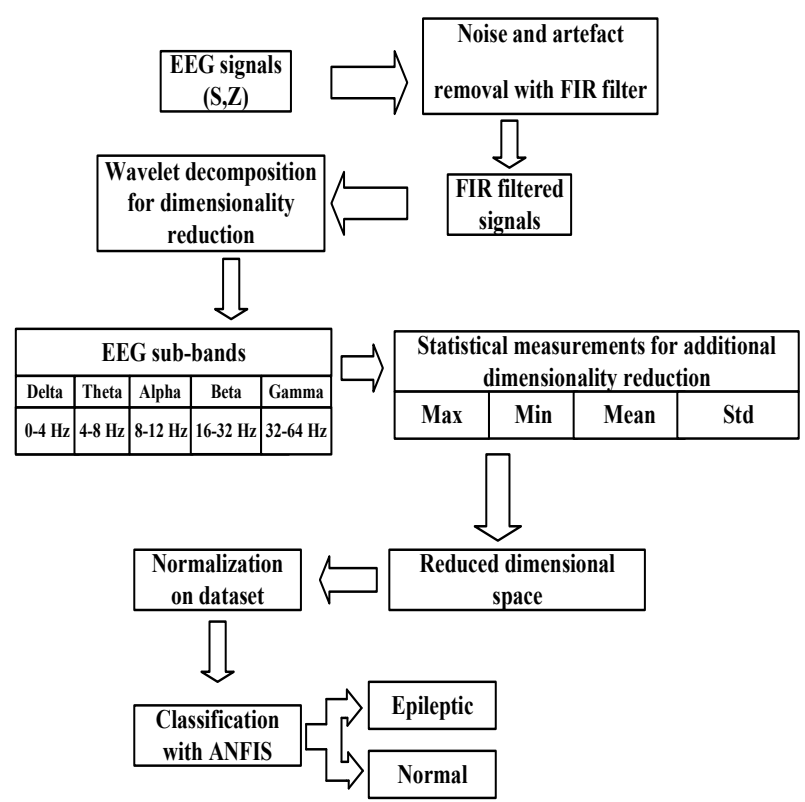

Fig. 1. Block scheme for the proposed algorithm

The filters are divided on analog and digital filters, where digital filters are classified in two main categories that are based on the length of their impulse response, namely Finite Impulse Response (FIR) filters and Infinite Impulse Response (IIR) filters $[2,3]$. Each class has its own characteristics and implementation needs. In this research the main focus is on the FIR filter.

FIR filters are designed by direct approximation of the magnitude or the impulse response. There are two common methods that are used: the windowed Fourier series method and the frequency sampling method. In this research, our focus will be on the windowed Fourier series method [3].

The window functions not only can be used to smoothen the discontinuities of the signal, but also they include specific characteristics in the frequency response. To achieve the same set of filter specifics, different windows need different filter coefficients [2].

One of the major difficulties in analysis of EEG signals is the presence of the artefacts. This disturbance represent serious obstructing factor that prohibits further processing to identify useful diagnostic features [4].

In this study, band-pass FIR filter with Hamming window is used as it is shown in Figure 2 [2]. Its main characteristics are: two cutoff frequencies ( $\mathrm{Fc} 1$ and $\mathrm{Fc} 2$, respectively), stopband attenuations and passband attenuation. The overall band of frequencies are defined by the Nyquist frequency, i.e. Fs/2 [2]. 


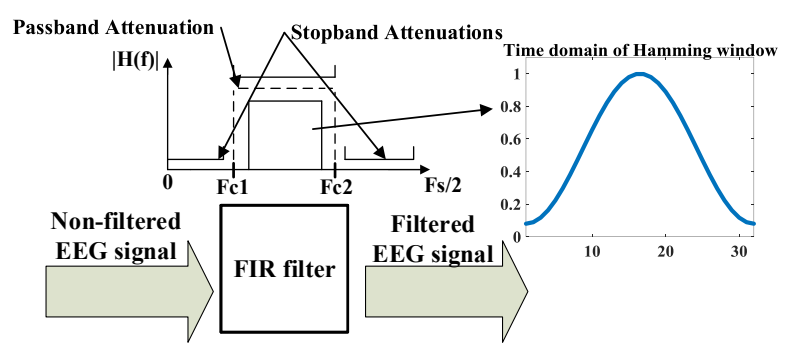

Fig. 2. Band-pass FIR filter with Hamming window.

\subsection{Wavelet analysis for feature extraction}

The frequency content of EEG signal provides useful information than time domain representation [19]. The wavelet transform gives us multi-resolution description of a non-stationary signal such as EEG signals [19].

Wavelets can be literally defined as "small" waves that have limited duration and "zero" average values. They are mathematical functions capable of localizing a function or a set of data in both time and frequency. The wavelet transform is an effective tool in signal processing due to its attractive properties such as time-frequency localization (obtaining a signal at particular time and frequency, or extracting features at various locations in space at different scales) and multi-rate filtering (differentiating the signals having various frequency). Using these properties one can extract the desired features from an input signal characterized by certain local properties in time and space [6].

The WT is defined as the integral of the signal $x(t)$ multiplied by scaled, shifted versions of a basic wavelet function $\psi(t)$, a real-valued function whose Fourier transform satisfies the criteria:

$$
C(a, b)=\int_{R}\left(x(t) \frac{1}{\sqrt{a}} \psi\left(\frac{t-a}{b}\right) d t,\right.
$$

where $a$ is the so-called scaling parameter, $b$ is the time localization parameter. Both $a$ and $b$ can be continuous or discrete variables [7].

Multiplying each coefficient by a properly scaled and shifted wavelet yields the constituent wavelets of the original signal. For signals of finite energy, continuous wavelet synthesis provides the reconstruction formula:

$$
x(t)=\frac{1}{K_{\psi}} \int_{R} \int_{R^{+}} C(a, b) \frac{1}{\sqrt{a}} \psi\left(\frac{t-a}{b}\right) \frac{d a}{a^{2}} d b .
$$

Related to the wavelet $\psi$, which is used to describe the details (high-scale/low frequency con- tent) in the decomposition, a scaling function $\varphi$ is used to define the approximations (low-scale/high frequency content) [7].

To avoid complicated computations when operating at every scale of the CWT, scales and positions can be selected based on a power of two, i.e. dyadic scales and positions. The DWT analysis is more efficient and just as accurate. In this scheme, $a$ and $b$ are given as:

$$
(j, k) \in Z^{2}: a=2^{j}, b=k 2^{j}, Z=\{0, \mp 1, \mp 2, \ldots\} .
$$

Let us define:

$$
\begin{aligned}
(j, k) \in Z^{2}: & \psi_{j, k}(t)=2^{-1} \psi\left(2^{-j} t-k\right), \\
\varphi_{j, k}(t) & =2^{-2} \varphi\left(2^{-j} t-k\right) .
\end{aligned}
$$

A wavelet filter with impulse $g$ plays the role of the wavelet $\psi$, and a scaling filter with impulse response $h$ plays the role of scaling function $\varphi$. Then the discrete wavelet analysis can be described mathematically as:

$$
C(a, b)=c(j, k)=\sum_{n \in Z} x(n) g_{j, k}(n),
$$

where $a=2^{j}, b=k 2^{j}, j, k \in N$ and discrete synthesis:

$$
x(t)=\sum_{j=Z} \sum_{k=Z} c(j, k) \psi_{j, k}(t) .
$$

The detail at level $j$ is defined as:

$$
D_{j}(t)=\sum_{\mathrm{k} \in Z} c(j, k) \psi_{j, k}(t)
$$

and the approximation at level $J$ :

$$
A_{J-1}=\sum_{j>J} D_{j}
$$

Obviously, the following equations hold:

$$
\begin{aligned}
& A_{J-1}=A_{J}+D_{j} . \\
& x=A_{J}+\sum_{j>J} D_{j}
\end{aligned}
$$

In practice, the decomposition can be determined iteratively, with successive approximations being computed in turn, so that a signal is decomposed into many lower-resolution components [7].

This is known as the wavelet decomposition tree. By using reconstruction filters and up sampling, we can reconstruct the signal constituents at each level of the decomposition [7]. 
In this study Daubechies wavelet [5] function is used which represent one of the frequently used wavelets which satisfies the conditions of orthogonality, which allows reconstruction of the signals from the wavelet coefficients.

The Daubechies wavelet system [5], a higher order generalization of Haar's wavelet, was shown to have superior smoothing effect on signals. The first order Daubechies wavelet is actually the Haar wavelet. Daubechies wavelets are designed to have $N / 2$ vanishing moments where $N$ is the number of wavelet coefficients [8].

We use Daubechies wavelets of order $2(\mathrm{db} 2)$ because of the suitability of our problem. They have two vanishing moments, and the filter coefficients are represented with the equation (9):

$$
\begin{aligned}
& h(z)=h_{-2} z^{2}+h_{-1} z+h_{0}+h_{1} z^{-1} \\
& g(z)=-h_{1} z^{2}+h_{0} z-h_{-1}+h_{-2} z^{-1}
\end{aligned}
$$

where $h_{-2}=\frac{1+\sqrt{3}}{4 \sqrt{2}}, h_{-1}=\frac{3-\sqrt{3}}{4 \sqrt{2}}, \quad h_{0}=\frac{3+\sqrt{3}}{4 \sqrt{2}}$ and $h_{1}=\frac{1-\sqrt{3}}{4 \sqrt{2}}$ are the values of filter coefficients [9].

\subsection{Adaptive neuro-fuzzy inference system}

The adaptive neuro-fuzzy inference system (ANFIS) was firstly introduced by Jang in 1993 [10]. It is an adaptive neural network that mimics the reasoning of either Sugeno or Tsukamoto fuzzy models $[10,13,14]$.

The structure of an ANFIS network for twoinput first-order Sugeno fuzzy model with two rules is given on Figure 3.

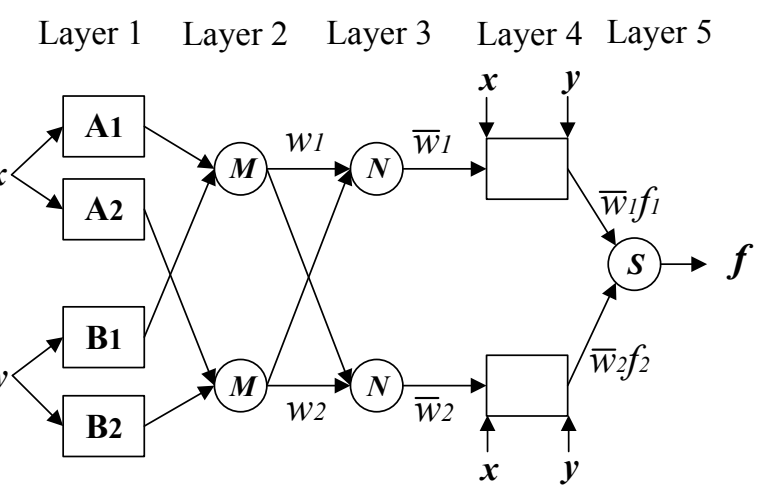

Rule1: if $\mathrm{x}$ is $\mathrm{A} 1$ and $\mathrm{y}$ is $\mathrm{B} 1$ then $f=p 1 x+q 1 y+r 1$ Rule2: if $\mathrm{x}$ is $\mathrm{A} 2$ and $\mathrm{y}$ is $\mathrm{B} 2$ then $f=p 2 x+q 2 y+r 2$

Fig. 3. ANFIS architecture

There are five layers, where the Layer 1 is an adaptive layer, which contains the input membership functions of the fuzzy system. These membership functions are adapted during the process of training. Layer 2 contains fixed nodes, whose output is the product of all incoming signals. Layer 3 also consists of fixed nodes, which calculates the ratio of the $i^{\text {th }}, \mathrm{s}$ rule firing strength to the sum of all rules' firing strengths (normalized firing strengths). Layer 4 contains adaptive nodes where the consequent parameters of the output Sugeno functions are trained [10].

The initial membership functions and rules for the fuzzy inference system can be designed by employing human expertise about the target system to be modeled. ANFIS can then purify the fuzzy ifthen rules and membership functions to describe input-output behavior of a complex system. Jang [10] showed that even if human expertise is not available, it is possible to intuitively set up practical membership functions and employs the neural training process to generate a set of fuzzy if-then rules that approximate a desired data set [4].

The ANFIS model uses hybrid learning algorithm in order to find the optimal parameters of the same model. It is composed of two phases:

- In forward pass of the hybrid learning algorithm, node outputs values go forward until layer 4 and the consequent parameters are identified by the least squares method.

- In the backward pass, the output errors are propagated backward and the premise para are updated by gradient descent method $[7,10,13$, 14].

\section{ALGORITHM FOR DETECTION OF EPILEPSY USING THE ANFIS CLASSIFIER}

On Figure 4 the overall algorithm for detection of epilepsy using ANFIS is given.

\subsection{Input data and FIR filtering of the signals}

The data used in this study was provided by the University of Bonn, given in [16]. This collection contains EEG data coming from three different events, namely, healthy subjects, epileptic subjects during seizure-free intervals (known as interictal states) and epileptic subjects during a seizure (ictal states). The collection contains five datasets identified as: $\mathrm{O}, \mathrm{Z}, \mathrm{F}, \mathrm{N}$ and $\mathrm{S}$; each set holds 100 segments of EEG signals of 23.6 seconds. The sampling frequency of these signals is $173.61 \mathrm{~Hz}$, so each segment contains 4097 samples. Sets $\mathrm{O}$ and Z were obtained from healthy subjects with eyes open and closed, respectively; sets F and N were obtained during interictal states in different zones of the brain and set $\mathrm{S}$ was taken from a subject during ictal state. 
In order to make comparison with some of the works described in section 1 , sets $\mathrm{Z}$ and $\mathrm{S}$ were used only for the results reported here [14, 27]. For analysis, two segments are compared in order to visualize the differences of healthy subject and epileptic subject as shown in Figure 5.

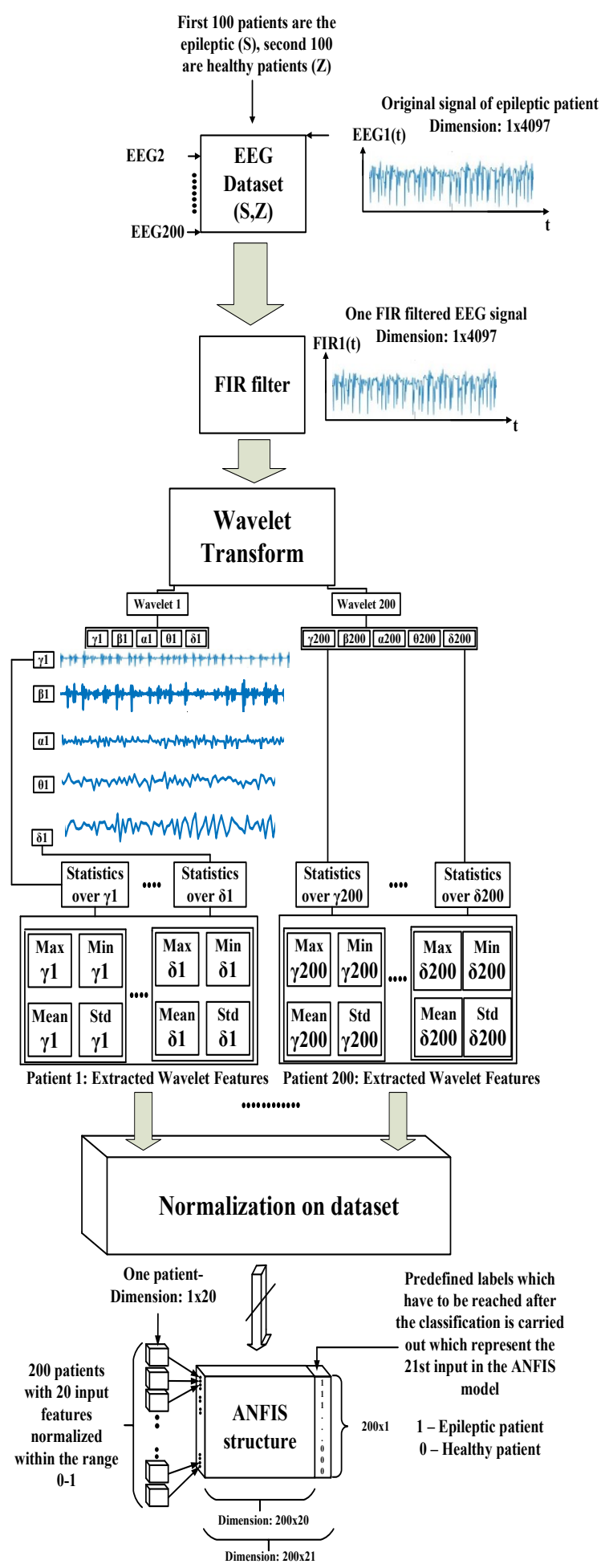

Fig. 4. Detailed analysis for the overall algorithm from Figure 1

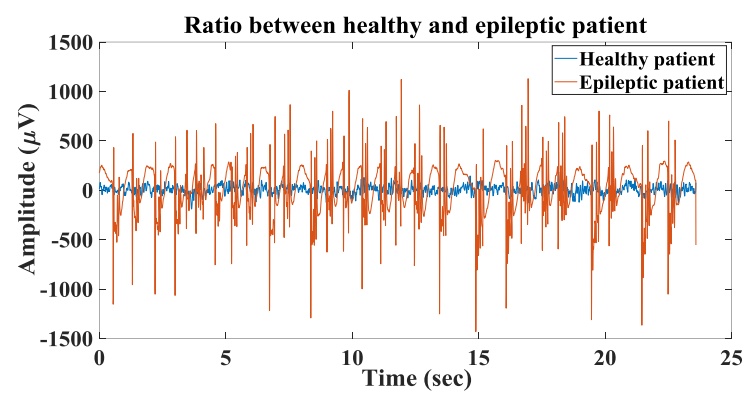

Fig, 5. Ratio between EEG signals of healthy and epileptic patient

As we can see, the signal from the epileptic patient has bigger oscillations, i.e. they have sudden transitions along with higher amplitude peaks than the signal from the healthy patient.

The next step of the overall algorithm is filtering of EEG signals, i.e. defining preprocessing technique which will allow reduction of artefacts which is key factor in the analysis of the medical signals [18].

As it was stated in Section 2.1, band-pass FIR filter with the Hamming window is used $[2,3]$. As we said, it characterizes with two cutoff frequencies, namely, lower cutoff frequency $\mathrm{Fc} 1$ and higher cutoff frequency Fc2. In our case they are $1 \mathrm{~Hz}$ and $60 \mathrm{~Hz}$, respectively, and this is in order to eliminate the artefacts that have corrupted the EEG signals [19].

Below $1 \mathrm{~Hz}$ are the artefacts that are coming from the human body, and above $60 \mathrm{~Hz}$ is the power line noise. On Figure 6(a) and Figure 6(b) ratio between filtered and non filtered signals of healthy patient and epileptic patient is shown respectively.

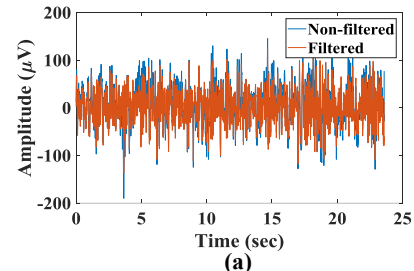

(a)



(b)
Fig. 6. Ratio between filtered and non-filtered EEG signals for (a) healthy patient and (b) epileptic patient

\subsection{Feature extraction using} Discrete Wavelet Transform (DWT)

Our next step from the algorithm is feature extraction with DWT $[13,14]$. The number of decomposition levels is chosen to be 4 . The levels are chosen such that those parts of the signal that correlate well with the frequencies required for classification of the signal are retained in the wavelet coefficients 
$[7,13,14]$. After the DWT, the signal is decomposed in details D1-D4 and one final approximation $\mathrm{A} 4$, as it is shown in Figure 7.

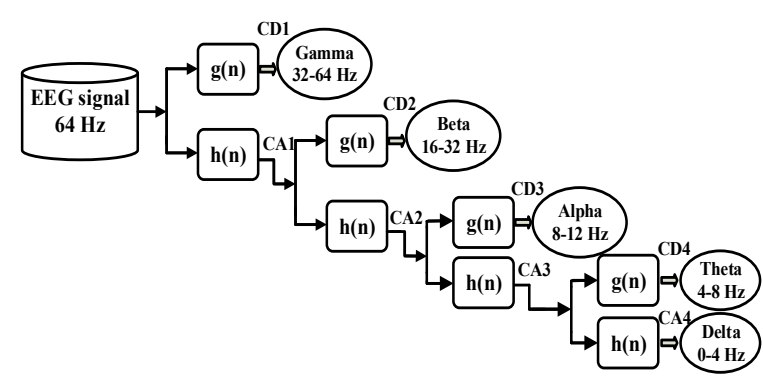

Fig. 7. Wavelet procedure for 4 levels of decomposition

The wavelet coefficients are calculated using Daubechies wavelets of order $2(\mathrm{db} 2)$ in MATLAB [20]. For visual analysis, the multistage decomposition on one signal from an epileptic patient are given on Figure 8.

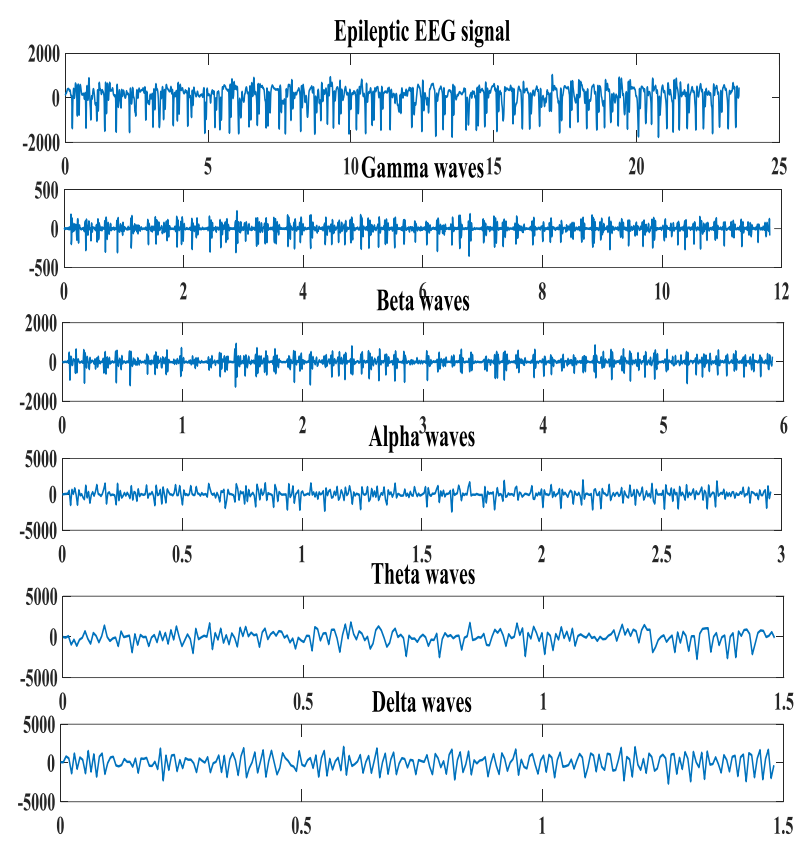

Fig. 8. Wavelet decomposition with Daubechies of order 2 on epileptic patient

Table 1 represents the frequencies that correspond to the different levels of decompositions for $\mathrm{db} 2$ with sampling frequency of $173.61 \mathrm{~Hz}$. We can see that the approximation coefficients CA4 are correctly placed within the range of $\delta(0-4 \mathrm{~Hz})$ brain waves, CD4 are placed in $\theta(4-8 \mathrm{~Hz}), \mathrm{CD} 3$ in $\alpha(8$ $12 \mathrm{~Hz}), \mathrm{CD} 2$ in $\beta(16-32 \mathrm{~Hz})$, and lastly, CD1 are placed within the range of $\gamma(32-64 \mathrm{~Hz})$ brain waves [7].
Ta ble 1

Frequencies corresponding to different levels of decomposition for Daubechies 2 with sampling frequency of $173.61 \mathrm{~Hz}$

\begin{tabular}{ccc}
\hline \hline $\begin{array}{c}\text { Decomposed } \\
\text { signal }\end{array}$ & $\begin{array}{c}\text { Frequency range } \\
\text { (Hz) }\end{array}$ & $\begin{array}{c}\text { Decomposition } \\
\text { level }\end{array}$ \\
\hline CD1 & $43.40-86.80$ & 1 (gamma) \\
CD2 & $21.7-43.40$ & 2 (beta) \\
CD3 & $10.85-21.7$ & 3 (alpha) \\
CD4 & $5.425-10.85$ & 4 (theta) \\
CA4 & $2.7125-5.425$ & 4 (delta) \\
\hline \hline
\end{tabular}

For additional dimensionality reduction of the dataset, statistical analysis of the wavelet coefficients is made. The following statistical measurements are used to represent time-frequency distribution of the EEG signals:

- Maximum of the wavelet coefficients in each subband.

- Minimum of the wavelet coefficients in each subband.

- Mean of the wavelet coefficients in each subband.

- Standard deviation of the wavelet coefficients in each subband.

Now, instead of having dataset with bigger dimensionality, we have dataset with reduced dimension. The dimension of the dataset is $200 \times 20$, i.e. 200 EEG segments along with 20 extracted features (4 statistical measurements $\times$ number of extracted coefficients $=20$ features for each EEG segment).

\subsection{ANFIS for classification of EEG signals}

Before the process of training and testing on the ANFIS classifier, all the columns of our dataset, i.e. the features, are normalized within the range from 0 to 1 , in order to achieve stable convergence on the weighted factors of the neural network during the training process. This is also called a feature scaling method which represents our next step of the overall algorithm. The min-max normalization technique is used for normalizing the input features [21].

The ANFIS classifier is trained with the hybrid algorithm $[7,10,13,14]$ whereas the 20 features are used as input patterns which represents the EEG signals. As this is a supervised learning problem (we have the information of the output labels), we define output vector which represents the $21^{\text {st }}$ column, i.e. the segments from the epileptic patients are labeled with ones, and the segments of the healthy patients 
are labeled with zeros. The overall dataset is divided onto training set for training the ANFIS model, and test set for testing the accuracy, with the ratio of $70 \%-30 \%$, respectively.

Before we start the training process, we define the initial ANFIS structure in MATLAB [22], and as a partitioning method of the input space, we use grid partitioning [10]. The ANFIS structure consists of membership functions divided in three regions, namely, small, medium and big [14] that are assigned to every input feature, i.e. generating $3^{20}=$ 3486784401 if-then rules. According to this, we face the problem called "curse of dimensionality" [10]. In order to avoid this problem, we define a different way of dividing the ANFIS structure into many substructures [22]. The ANFIS structure is divided according to the input features, in our case it is divided into 7 substructures. The substructures from 1 to 6 receive 3 input features that will lead to $3^{3}=27$ if-then rules, and the last one will have $3^{2}=9$ if-then rules. With this, we surpassed this major obstacle (Figure 9).

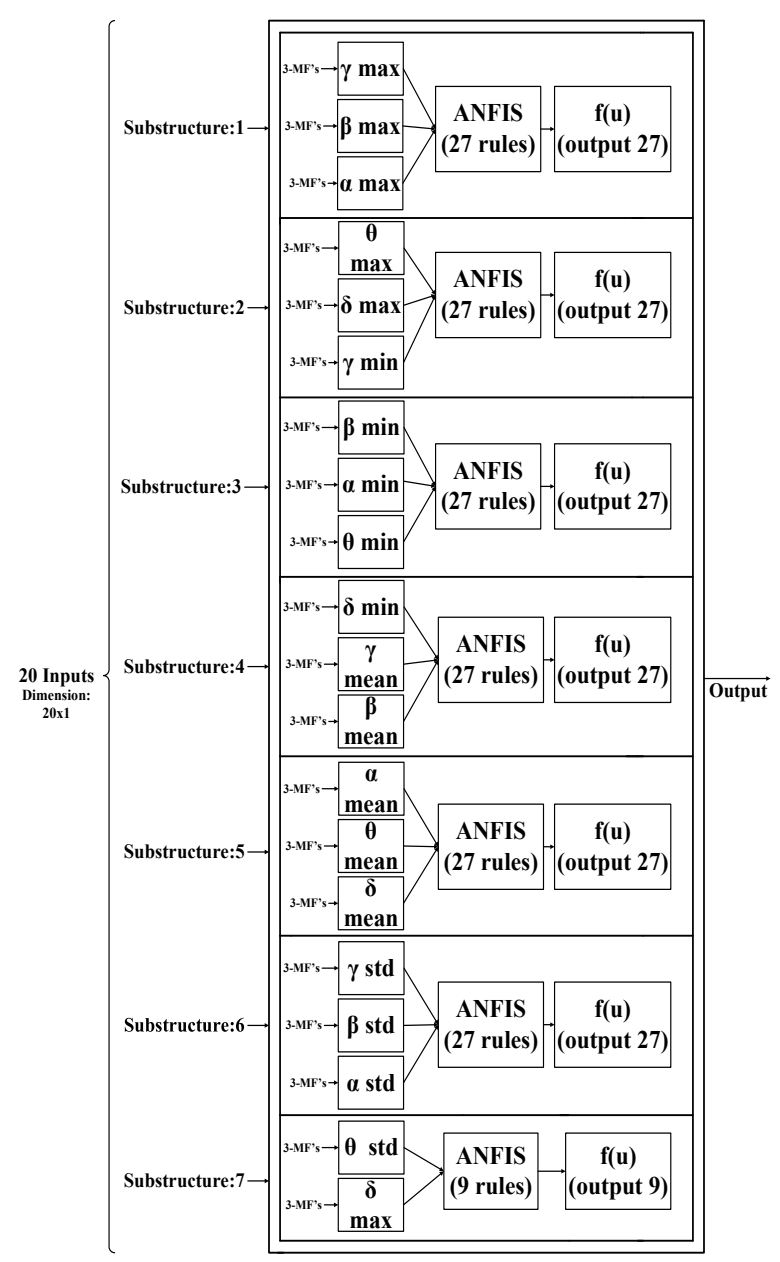

Fig. 9. Division of ANFIS onto 7 substructures
For the input membership functions we use generalized bell-shaped membership functions (gbellmf). From illustrative character, the initial membership functions for the second and seventh substructures are shown on Figure 10(a) and (b), respectively. In the second substructure the input parameters are: maximum of $\theta$, maximum of $\delta$ and minimum of $\gamma$ wavelet coefficients, and in the seventh substructure we have only two features as input parameters, namely: $\theta$ standard deviation and $\delta$ standard deviation of the wavelet coefficients.



(a)



(b)
Fig. 10. Initial generalized bell shaped membership functions for substructure 2 (a) and substructure 7 (b)

The model is trained with different number of epochs and the accuracy is defined according to the error measure $R$ for the overall ANFIS [14]. After the training, the parameters of the ANFIS network are changed, as shown in Figure 11(a) for the second substructure and in Figure 11(b) for the seventh substructure.

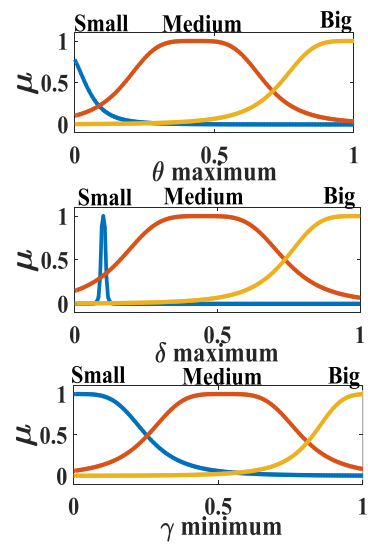

(a)

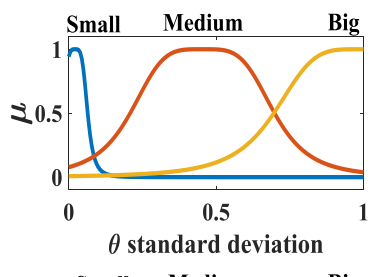

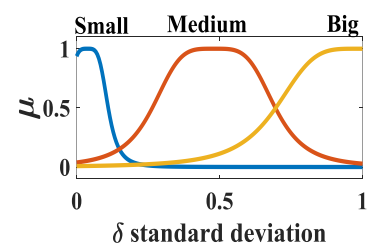

(b)
Fig. 11. Final generalized bell shaped membership functions after training for substructure 2 (a) and substructure 7 (b) 
On Figure 12(a) the ratio between the accuracies of the training and testing set are shown, while on Figure 12(b) the ratio between root mean square errors (RMSE) on training and testing sets during different number of epoch is shown.
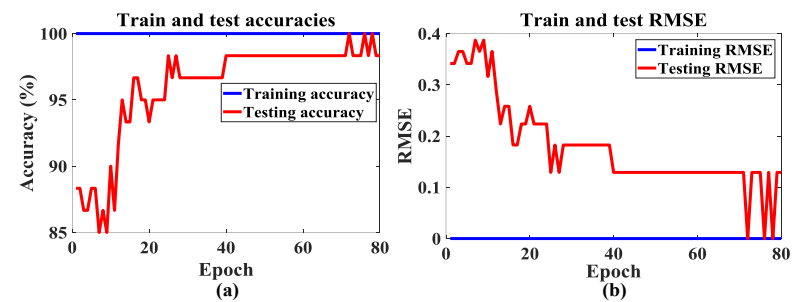

Fig. 12. Training and testing accuracies (a); training and testing RMSEs (b) generated for different number of epochs

From Figure 12 we see that in three moments we get $100 \%$ accuracy and zero RMSE on testing. This suggests us that if we over train the ANFIS model, it will result in overfitting [23], which will reduce the predictive power of the ANFIS or any neural network. According to this, for small datasets like in our case, it is enough to train the model with 60 epochs in order to get satisfactory results with testing accuracy of $98.3 \%$ and optimal RMSE of 0.191 . Figure 13 presents the accuracy for 60 epochs.

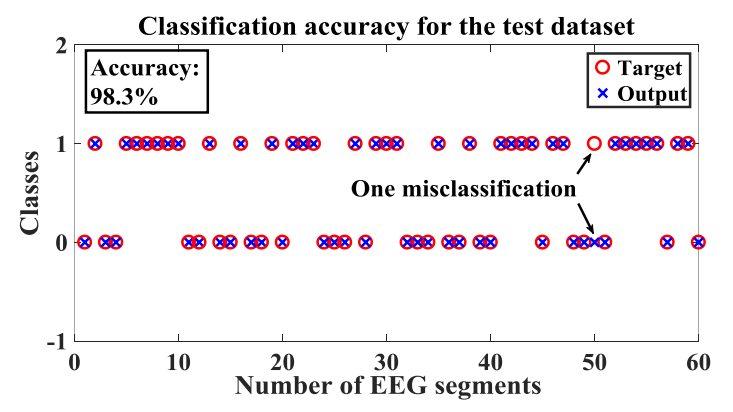

Fig. 13. Test set accuracy for 60 epochs

Also, we tested the ANFIS model on the overall dataset as shown in the Figure 14.

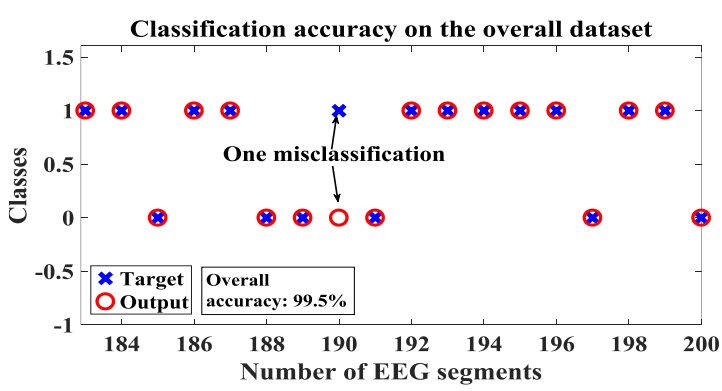

Fig. 14. Overall set accuracy for 60 epochs
As we can see, we get even better results on classifying all the EEG segments of $99.5 \%$ accuracy. The classification results for the ANFIS model are shown in Table 2 for the testing dataset ( 1 is an epileptic patient, and 0 denotes a healthy patient).In this table, each cell contains the raw number of exemplars classified for the corresponding combination of targeted and actual network outputs. As we can see, we make 1 misclassification, i.e. classifying an epileptic patient as a healthy patient.

Table 2

Confusion matrix for 60 epochs on the test dataset

\begin{tabular}{ccc}
\hline \hline \multirow{2}{*}{ Target } & \multicolumn{2}{c}{ Output } \\
& Set Z & Set S \\
\hline Set Z & 26 & 1 \\
Set S & 33 & 0 \\
\hline \hline
\end{tabular}

We briefly describe some work that report results using Bonn database [16], which is used in our research.

E. Juarez-Guerra et al. [17] presented the results of a model based wavelet analysis and neural networks for identification of seizure events and epilepsy. They've tested several filters, wavelets and wavelet transformations, namely, Haar, $\mathrm{db} 2$ and $\mathrm{db} 4$. Six features have been used to train the FeedForward Artificial Neural Network (FF-ANN): mean, absolute median and variance of delta and alpha sub-bands. When using the whole segments for training, $93.23 \%$ of accuracy has been achieved. Whereas when using sub-segments for training, $99.26 \%$ of accuracy has been achieved. Thus, the accuracy rates of the ANFIS model presented for this application were found to be higher when subsegments for training are used (in our case we only use sub-segments for training) than E. JuarezGuerra et al. [17].

I. Omerhodzic et al. [24] presented algorithm for classification of EEG signals based on WaveletNeural Network classifier. DWT with multiresolution analysis (MRA) based on Daubechies of order $4(\mathrm{db} 4)$ has been applied to decompose the EEG signals at resolution levels of the components of the EEG signal. They used percentage distribution of the energy as features of the EEG signals at different resolution levels. The classifier has been used to classify those extracted features to identify the EEGs type according to the percentage distribution 
of energy features. They achieved $94 \%$ overall acuracy, so that our ANFIS model showed higher accuracy than the study proposed by I. Omerhodzic [24] (Table 3).

\section{Tab le 3}

\section{Comparison of the accuracy results between our and other studies}

\begin{tabular}{lcc}
\hline \hline Accuracy (\%) & $\begin{array}{r}\text { Test set } \\
\text { accuracy }\end{array}$ & $\begin{array}{c}\text { Overall set } \\
\text { accuracy }\end{array}$ \\
\hline This study & 98.33 & 99.5 \\
E. Juarez - FFANN & 99.26 & 93.23 \\
$\begin{array}{l}\text { I. Omerhodzic Wavelet + Neural } \\
\text { Network }\end{array}$ & $/$ & 94 \\
\hline \hline
\end{tabular}

We have to note that the authors in [14] also use wavelet transform for feature extraction and ANFIS for classification of EEG signals, but our approach differs from theirs as we use conventional filtering method (FIR), as well as normalization of the data after feature extraction. When we compare only the numbers, our approach gives similar, or somewhere even better results from theirs. They get $98.63 \%$ test accuracy of the test set $\mathrm{Z}$ (healthy), and $98.25 \%$ test accuracy on the test set $S$ (epileptic), whereas we get $98.33 \%$ accuracy on the test set containing both healthy and epileptic patients. Nevertheless, we have to strictly note that they make 5 class classification, which differs from our 2 class classification, which is why we did not summarize their results in Table 3.

\section{CONCLUSION}

This paper presented the use of ANFIS for classification of the two classes EEG signals. The input parameters in the ANFIS model were the extracted features of the wavelet coefficients. The proposed ANFIS combined the adaptive capability of the neural networks and the qualitative approach in the fuzzy logics. The ANFIS classifier which was trained with 60 epochs reached $98.3 \%$ accuracy on the test set, and $99.5 \%$ classification accuracy on the overall dataset. We also made comparison with the results presented in other related works, whereas we can conclude that the proposed algorithm can be successfully used in classification of EEG signals.

\section{REFERENCES}

[1] Rajendra Acharya, U., Vinitha Sree, S., Swapna, G., Roshan Joy Martis, Jasjit S. Suri: Automated EEG analysis of epilepsy, A review, Knowledge-Based Systems, 45, pp. 147-165 (2013).

[2] Sinha, P.: Speech Processing in Embedded Systems, Chapter 2: Signal Processing Fundamentals, Springer Science + Business Media, 2010.

[3] Stanley H. Mneney: An Introduction to Digital Signal Processing: A Focus on Implementation, River Publishers, 2008.

[4] Najumnissa, D., Rangaswamy, T. R.: Detection and Classification of Epilepsy Seizures Using Wavelet Feature Extraction and Adaptive Neuro-Fuzzy Inverence System, B S Adbur Rahman University, Chennai, India, May 2012.

[5] Phan, Quan: Design of Vibration Inspired Bi-orthogonal Wavelets for Signal Analysis, Houston, Texas, April 2012.

[6] Adeli, H.; Ziqin Zhou; Nahid Dadmehr: Analysis of EEG records in an epileptic patient using wavelet transform, Journal of Neuroscience Methods, 123 (1) 69-87 (2013).

[7] Subasi, Abdulhamit: Application of adaptive neuro-fuzzy inference system for epileptic seizure detection using wavelet feature extraction, Department of Electrical and Electronics Engineering, Kahramanmaras Sutcu Imam University, Turkey, December 2005.

[8] Adeli, Hojjat; Ghosh-Dastidar, Samanwoy: Automated EEG-Based Diagnosis of Neurological Disorders: Inventing the Future of Neurology, Taylor and Francis Group, 2010.

[9] Getreuer, Pascal: Filter Coefficients to Popular Wavelets, May 2006.

[10] Jyh-Shing Roger Jang, Chuen-Tsai Sun, Eiji Mizutani: Neuro-Fuzzy and Soft Computing - A Computational Approach to Learning and Machine Intelligence, Prentice Hall Upper Saddle River, NJ, 1997.

[11] Usher, J., Campbell, D., Vohra, J.; Cameron, J., A Fuzzy Logic - Controlled Classifier for use in implantable cardioverter defibrillators, Pace-Pacing Clin Electrophysiol, 22, pp. 183-6 (1999).

[12] Belal, S. Y.; Taktak, A. F. G.; Nevill, A. J.; Spencer, S. A.; Roden, D.; Bevan, S.: Automatic Detection of Distorted Plethysmogram Pulses in Neonates and Pediatric Patients Using an Adaptive-Network-Based Fuzzy Inference System, Artif Intell Med, 24, pp. 149-65 (2002).

[13] Güller, Ïnan; Derya Übeyli, Elif: Application of adaptive neuro-fuzzy inference system for detection of electrocardiographic changes in patients with partial epilepsy using feature extraction, Expert Systems with Applications, 27, 3. 323-330 (2004).

[14] Güller, Ïnan; Derya Übeyli, Elif: Adaptive neuro-fuzzy inference system for classification of EEG signals using wavelet coefficients, Faculty of Education, 06500 Thenikokullar, Ankara, Turkey, April 2005.

[15] Virant-Klun, I., Virant, J.: Fuzzy logic alternative for analysis in the biomedical sciences, Comput Biomed Res., 32, pp. 305-21 (1999). 
[16] Andrzejak, R. G., Lehnertz, K., Rieke, C., Mormann, F., David, P., Elger, C. E.: Indications of nonlinear deterministic and finite dimensional structures in time series of brain electrical activity, http://epileptologie-bonn.de/cms/f ront_content.php?idcat $=193 \&$ lang $=3$

[17] Juarez-Guerra, E., Alarcon-Aquino, V., Gomez-Gil, P.: Epilepsy Seizure Detection in EEG Signals Using Wavelet Transforms and Neural Networks, In: Elleithy K., Sobh T. (eds), New Trends in Networking, Computing, E-learning, Systems Sciences, and Engineering. Lecture Notes in Electrical Engineering, vol. 312. Springer, Cham., Department of Computing, Electronics, and Mechatronics, December 12-14, 2013

[18] Wang, L., Xue, W., Li, Y., Luo, M., Huang, J., Cui, W., Huang, C.: Automatic Epileptic Seizure Detection in EEG Signals Using Multi-Domain Feature Extraction and Nonlinear Analysis, Entropy-Article, 19 (6), 222, 27 May 2017, https://doi.org/10.3390/e19 060222

[19] Nakate, Ashwini; Bahirgonde, P. D.: Feature extraction of EEG signals using wavelet transform, International Journal of Computer Applications (0975-8887), Vol. 124, No. 2, August 2015.

[20] https://www.mathworks.com/help/wavelet/examples/mul tisignal-1-d-wavelet-analysis.html

[21] Zuriani Mustaffa; Yuhanis Yusof: A Comparison of Normalization Techniques in Predictiong Dengue Outbreak, Internation Conference on Business and Economics Research, Kuala Lumpur, Malaysia, vol. 1, pp. 345-349 (2011).

[22] https://www.mathworks.com/matlabcentral/fileexchange/ 62245-anfis-classifier

[23] Domingos, P.: A Few Useful Things to Know about Machine Learning, Department of Computer Science and Engineering, University of Washington, Seattle, USA. Communications of the ACM, Vol. 55, No. 10, pp. 78-87 (2012).

[24] Omerhodzic, I., Avdakovic, S., Nuhanovic, A., Dizdarevic, K.: Energy Distrubution of EEG Signals: EEG Signal Wavelet-Neural Network Classifier, https://arxiv.org/pdf/1307.7897

[25] Tingxi Wen; Zhongnan Zhang: Effective and Extensible Feature Extraction Method Using Genetic AlgorithmBased Frequency-Domain Feature Search for Epileptic EEG Multi-classification, Medicine (Baltimore), 96, 19 (2017). Doi: 10.1097/MD.0000000000006879

[26] Prabhpreet Kaur Bhatia and Anurag Sharma: Epilepsy seizure detection using wavelet support vector machine classifier, International Journal of Bio-Science and Bio-Technology, Vol. 8, No. 2, pp. 11-22 (2016). http://dx. doi.org/10.14257/ijbsbt.2016.8.2.02

[27] Ahmed Fazle Rabbi and Reza Fazel-Rezai: A Fuzzy Logic System for Seizure Onset Detection in Intracranial EEG, Hindawi Publishing Corporation Computational Intelligence and Neuroscience, 4 November 2011.

[28] Kumar, A., Mohan Saini, L.: Detection of epileptic seizure using discrete wavelet transform of EEG signal, International Journal of Soft Computing and Artificial Intelligence, Vol. 3, Issue 1, pp. 49-53, May 2015, ISSN: 2321404X.

[29] Baxt, W. G.: Use of an artificial neural network for data analysis in clinical decision making: the diagnosis of acute coronary occlusion, Neural Comput, 2, pp. 480-9 (1990).

[30] Miller, A. S., Blott, B. H., Hames, T. K.: Rewiev of neural network applications in medical imaging and signal processing, Med Biol Eng Comput, 30, pp. 449-464 (1992).

[31] Dubois, D., Prade H.: An Introduction to fuzzy systems, Clin Neurophysiol, 83 (5), 271-280 (1993).

[32] Kuncheva, L. I., Steimann F.: Fuzzy diagnosis, Artif Intell Med., 16, 2, pp. 121-128 (1999).

[33] Gajic, D., Djurovic, Z., Di Gennaro, S., Gustafsson, F.: Classification of EEG signals for detection of epileptic seizures based on wavelets and statistical pattern recognition, Biomedical Engineering: Applications, Basis and Communications, 26, 2 (2014), http://dx.doi.org/10.4015/S1016237214500215. 
